\title{
UN MENSAJE DE ESPERANZA A LOS PEQUEÑOS AGRICULTORES: LA RENTABILIDAD YA ESTÁ AL ALCANCE DE TODOS
}

\section{A MESSAGE OF HOPE TO SMALL FARMERS: THE PROFITABILITY IS NOW AVAILABLE TO EVERYONE}

\author{
Lacki Polan \\ Rua Bispo Dom José, 2051 apto 706 \\ Telef: (55-41) 3243-2366 Celular: (55-41) 9602-1239 \\ 80440-080 Curitiba - Paraná - Brasil \\ E-mails: Polan.Lacki@uol.com.bry Polan.Lacki@onda.com.br \\ Websites: www.polanlacki.com.br y www.polanlacki.com.br/agroesp
}

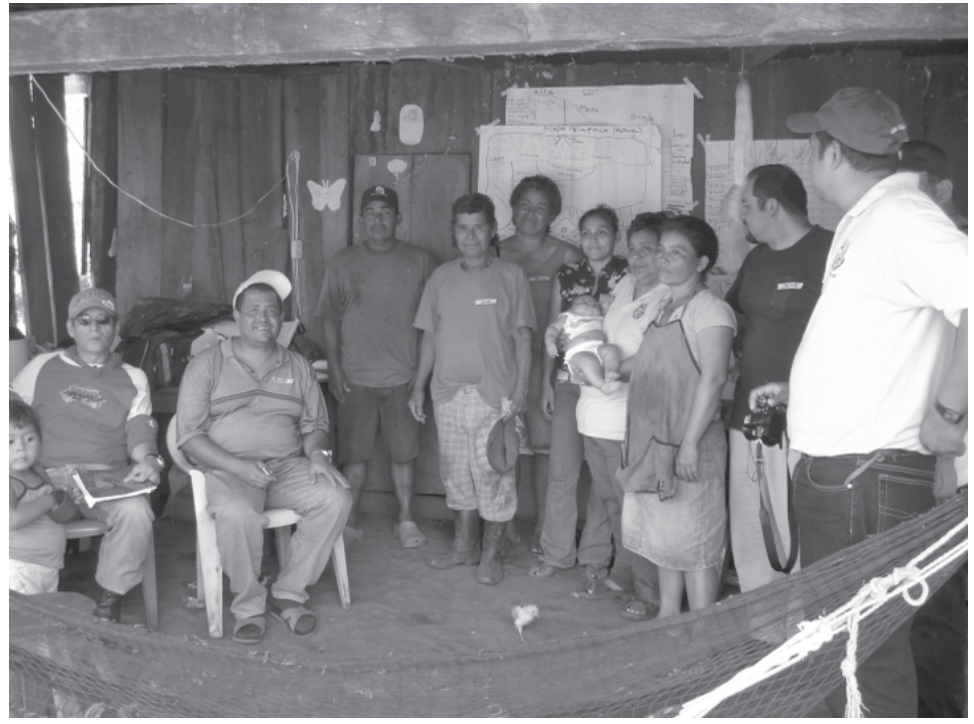

Empiezo este mensaje con la siguiente afirmación: En América Latina es muy poco o casi nada lo que los pequeños agricultores pueden esperar de sus gobiernos -- debilitados, endeudados, ineficientes y en muchos casos corrompidos. Y esto no es una suposición sino que una clara constatación de la ineficacia de las políticas públicas en pro del desarrollo rural. Así lo han demostrado, durante más de cinco décadas, los reiterados fracasos de sus muchísimos programas asistencialistas que no han sido capaces de reducir y mucho menos de erradicar la pobreza rural. En virtud de dicha ineficacia les sugiero, concreta y objetivamente, que no sigan perdiendo más tiempo con soluciones de parche que los mantienen eternamente dependientes del humillante paternalismo gubernamental. Con tal fin les sugiero que cambien de actitud y empiecen a construir un desarrollo más endógeno, más autodependiente y más autogestionario que los emancipe de esos engaños y demagogias populistas. Será mucho más constructivo que dediquen su valioso tiempo a asesorarse con un buen extensionista que les enseñe a ser más eficientes, a visitar su comunidad, a perfeccionarse estudiando textos sobre producción, administración rural y comercialización agrícola, a corregir las ineficiencias aún existentes en sus fincas, a aumentar y mejorar la calidad de la producción, a reducir los costos por kilogramo producido, a incorporar valor a las cosechas, a comprar insumos y vender lo que producen con menor intermediación. Y, como consecuencia de la correcta adopción de estas medidas "eficientizadoras", sencillamente no necesitar de las ineficaces "ayudas" gubernamentales. A quienes deseen analizar la posibilidad y conveniencia de adoptar este nuevo camino, de la esperanza, del rescate de la dignidad y de la autoestima, les sugiero leer críticamente algo tan sencillo como lo siguiente:

1) Para llegar a lo deseable es necesario partir de lo posible. Quienes conocen, en forma vivencial, las extraordinarias potencialidades productivas de nuestra agricultura, saben que para tener éxito económico en el negocio agrícola, no siempre ni necesariamente se requiere de altas decisiones políticas, créditos abundantes, grandes extensiones de 
tierra, inversiones en maquinaria de alto costo, ni de tecnologías sofisticadas. Muchísimo más importante y eficaz que lo anterior es evitar, corregir y/o eliminar las ineficiencias que, sin darse cuenta, la gran mayoría de los agricultores aún está cometiendo en la forma como produce, como administra sus fincas y como comercializa sus cosechas. Evitar, corregir o eliminar dichos errores cuesta muy poco pero tiene una sorprendente eficacia en el incremento de los ingresos de las familias rurales. En la era de los mercados globalizados ustedes tendrán que competir con los agricultores más eficientes del mundo y por esta razón necesitan volverse cada vez más eficientes. Sin embargo no podrán hacerlo de un solo golpe. Por esta razón les sugiero que...

2) Empiecen la "eficientización" productiva con tecnologías de costo mínimo. Con el fin de que todos los agricultores, especialmente los más pobres, puedan volverse más eficientes, la introducción de tecnologías más productivas debe ser realizada en forma gradual, empezando con las más sencillas y de menor costo. Después que éstas hayan sido correctamente adoptadas, ustedes aumentarán los rendimientos por hectárea y por animal. Con esta gradualidad "sacarán" de sus propias fincas - y no de la ventanilla del banco - el dinero necesario para adquirir los insumos de mayor costo que son utilizables en las etapas más avanzadas de tecnificación.

3) No siembren más hectáreas que aquellas que pueden cultivar con tecnologías que permitan obtener altos rendimientos. Como regla general es más conveniente cultivar, de manera correcta, una hectárea de maíz y cosechar en ella 8 toneladas que cultivar incorrectamente dos hectáreas y cosechar 4 toneladas en cada una de ellas. No críen más animales que aquellos que puedan desparasitar y alimentar adecuadamente, durante todo el año, con el fin de que ellos produzcan más leche y más crías. Es mejor tener una vaca genéticamente mejorada, desparasitada, sana y bien alimentada que produzca 20 litros de leche al día que tener 5 vacas hambrientas, con mastitis y llenas de parásitos que producen 4 litros cada una.

4) Huyan de los monocultivos y diversifiquen la producción agrícola y ganadera para volverse menos vulnerables a los riesgos de clima, mercado, plagas y enfermedades; ídem para generar alimentos diversificados e ingresos durante todo el año y con ello volverse menos dependientes del crédito. Quienes obtienen apenas una o dos cosechas (y uno o dos ingresos) al año, por supuesto que serán muy dependientes del crédito rural. Entonces, en vez de endeudarse innecesariamente y pagar intereses a los bancos hagan una eficiente diversificación productiva para que la finca genere ingresos más abundantes y más frecuentes durante el año. Los productores de vacunos, cabras y ovejas deberán, en primerísimo lugar, mejorar la productividad y la calidad de las pasturas para volverse menos dependientes del uso de raciones balanceadas que suelen ser muy caras. Los productores de ganado lechero, cerdos y aves deberán producir en sus propias fincas los ingredientes (maíz o sorgo, soya/soja, alfalfa, granos de girasol, yuca/mandioca, camote, etc.) y transformarlos en raciones balanceadas de muy bajo costo. Si ustedes ya producen estos ingredientes jamás los vendan al primer intermediario que aparezca en la finca; transfórmenlos en raciones y "véndanlas" a sus propias vacas lecheras, cerdos y pollos.

5) Depongan, de una vez por todas, el individualismo que está destruyéndolos económicamente y se junten con sus vecinos confiables para adquirir los insumos y para comercializar las cosechas en conjunto y con menor intermediación. A propósito observen como ustedes mismos, sin quererlo, actúan en contra de sus propios intereses económicos:

Ustedes pagan precios innecesariamente altos por los insumos porque los adquieren en forma individual, en pequeñas cantidades, del último eslabón de una larga cadena de intermediación y con alto valor agregado (las raciones balanceadas que ustedes compran del último intermediario, probablemente fueron fabricadas con los ingredientes que salieron de vuestras propias fincas o comunidades).

Pero ustedes mismos cuando venden sus cosechas hacen exactamente lo contrario y, por esta razón, reciben precios innecesariamente bajos porque venden al primer eslabón de la cadena de intermediación, las comercializan al por mayor y sin ningún valor agregado. El individualismo los volvió extremadamente frágiles y los condujo a la siguiente paradoja: cuando compran los insumos ustedes preguntan ¿cuánto cuesta? ¿Pero cuando se convierten en vendedores de sus cosechas siguen preguntando ¿cuánto me pagan? Es decir, por causa del individualismo, ustedes nunca son formadores de precios. Son ustedes quienes generan las riquezas, quienes trabajan más y arriesgan más, pero cometen el error de no apropiarse de dichas riquezas.

6) Asimismo júntense con sus vecinos para poseer en forma grupal la maquinaria de alto costo, que económicamente no se justifica poseerla en forma individual. Muchísimos agricultores se han endeudado innecesariamente para poseer maquinaria individual que la utilizan durante 10 días al año y que descansa los otros 355 días. Entonces y a modo de ejemplo, es mejor que un grupo de 10 pequeños productores tenga un buen tractor, una buena sembradora, una buena cosechadora y una buena pulverizadora. Desafortunadamente esto no ocurre porque cada agricultor quiere tener su propia maquinaria. En muchísimos casos el dinero que ustedes gastaron para adquirir la maquinaria individual es el dinero que, más adelante, les hará falta para comprar insumos necesarios para aumentar la productividad en la agricultura (semillas mejoradas, fertilizantes, inoculantes, pesticidas); ídem para mejorar los índices zootécnicos en la ganadería (mejoramiento de las pasturas ojalá con fertilizantes y riego, conservación de forrajes para los períodos de escasez, vacunas, semen, antiparasitarios, sales minerales). 
En resumen, la gradual y correcta adopción de estas seis medidas es una estrategia factible y eficaz para empezar a aumentar los rendimientos por hectárea y animal; y, como consecuencia de lo anterior, para reducir drásticamente los costos por kilogramo producido. Quienes logren esta reducción en los costos se verán menos afectados aún cuando los precios de venta de sus cosechas y animales sean muy bajos. Para el caso de los agricultores muy pequeños y pobres, esta gradualidad tecnológica (de menos a más, de lo sencillo a lo complejo, de lo barato a lo caro), es la única alternativa que les queda para volverse más eficientes y con ello aumentar, paso a paso, la producción y mejorar los ingresos familiares.

Estas prácticas, "eficientizadoras" de la producción propiamente tal y "reductoras" de sus costos son cada vez más imprescindibles para sobrevivir económicamente en la agricultura. Sin embargo, ellas son aún insuficientes. Para lograr un incremento significativo en sus ingresos, adicionalmente, será necesario que ustedes obtengan mejores precios en la comercialización de sus excedentes, y esto a su vez requiere que adopten las próximas cuatro medidas.

7) Realicen, también en forma gradual, la reconversión productiva reemplazando los cultivos/rubros que consumen los pobres por otros que son consumidos por los ricos. Es muy difícil que un agricultor con 5 o 10 hectáreas de tierra sembrando (para vender) yuca, papas, camote, calabaza o granos básicos pueda sobrevivir económicamente en la agricultura. Estos rubros de baja densidad económica consumidos principalmente por los pobres deberán ser reemplazados, en forma prudente y gradual, por otros productos que son consumidos por los ricos, porque éstos rinden mucho más ingresos por hectárea, como por ejemplo: alcachofas, espárragos, brócolis, tomates cereza, champiñones, melones y sandías, mangos, aguacates/paltas, guanábanas, frutillas/fresas, pitahayas, granadillas, piñas, hortalizas/huevos/pollos orgánicos, huevos de codornices, lechones para épocas de fiestas, miel de abejas, flores, plantas ornamentales, plantones de frutales, etc.

8) No vendan las cosechas sin mejorar su presentación y apariencia. Ustedes mismos podrán incorporar valor a sus productos primarios, empezando por aquellas medidas que, debido a su sencillez y bajo costo, pueden ser ejecutadas por sus propios familiares; como por ejemplo, limpiar, clasificar, fraccionar y envasar en bolsitas plásticas granos de frejoles, arvejas o lentejas; lavar raíces y tubérculos, clasificarlos por tamaño y apariencia $\mathrm{y}$ fraccionarlos en pequeñas cantidades o poner lechugas $\mathrm{o}$ brócolis en bandejitas individuales de polietileno y cubrirlas con películas transparentes. Es decir, incorporar ustedes mismos algo de valor a sus cosechas en vez de seguir delegando y "regalando" la etapa más rentable del agronegocio a las agroindustrias o a las grandes cadenas de supermercados como el Wall Mart y el Carrefour.

9) También en forma gradual, salten algunos eslabones de intermediación. Si actualmente venden al primer eslabón, en la próxima vez formen un grupo y comercialicen con el segundo eslabón... y así sucesivamente vayan acercándose a los consumidores finales.

10) Sin embargo, ojo: antes de incorporar valor a las cosechas y mejorar su comercialización no se olviden de producirlas con menores costos y con mejor calidad. La incorporación de valor agregado y una mejor comercialización no podrán hacer milagros. Las nueve medidas "eficientizadoras" recién sugeridas, producirán los efectos esperados si ustedes mejoran la calidad de sus materias primas y si reducen sus costos por kilogramo producido. Será muy difícil, por no decir imposible, que una leche de mala calidad (sucia, con bajo porcentaje de proteínas y grasas, contaminada con exceso de bacterias y con residuos de antibióticos) y producida con alto costo por litro, pueda ser transformada en queso, mantequilla/manteca o yogurt de excelente calidad y llegar a los mercados con precios competitivos. 